\title{
Exclusive breastfeeding and maternal employment in Ethiopia: A comparative cross- sectional study
}

\author{
Mekuanint Taddele ${ }^{1}$, Lakew Abebe ${ }^{2}$, Netsanet Fentahun ${ }^{2, *}$ \\ ${ }^{1}$ Ahmara Region Health Bureau, Bahir Dar, Ethiopia \\ ${ }^{2}$ Department of Health Education and Behavioral Sciences, College of Public Health and Medical Sciences, Jimma University, Jimma, Ethiopia
}

Email address:

netsanet_fentahun@yahoo.com (N. Fentahun), netsanet.fentahun@ju.edu.et (N. Fentahun)

To cite this article:

Mekuanint Taddele, Lakew Abebe, Netsanet Fentahun. Exclusive Breastfeeding and Maternal Employment in Ethiopia: A Comparative Cross- Sectional Study. International Journal of Nutrition and Food Sciences. Vol. 3, No. 6, 2014, pp. 497-503.

doi: $10.11648 /$ j.ijnfs.20140306.12

\begin{abstract}
Back-ground: Promotion of exclusive breastfeeding is the single most cost-effective intervention to reduce infant mortality in developing countries. Exclusive breastfeeding for the first six months has greater benefit than formula feeding for the prevention of mother to child transmission of HIV. In Ethiopia, the prevalence of exclusive breast feeding among infants less than 6 months is $49 \%$, with limited information on associated factors of exclusive breast feeding. Understanding the associated factors that influence exclusive breastfeeding is crucial to promote the practice in Ethiopia. Objective: To compare exclusive breastfeeding and its associated factors among employed and unemployed mothers in Injibara Town, Awi Zone, North west Ethiopia. Method: A community-based comparative cross-sectional study was conducted from March 24-April 14, 2013. A total of 524 mothers of children age $\leq 1$ year were included in the study. A structured, pretested and self-administered questionnaire was used to collect data. Descriptive statistics were performed to compare exclusive breastfeeding among employed and unemployed mothers. Multiple logistic regression analysis was conducted to identify independent predictors of exclusive breastfeeding. Results: The prevalence of exclusive breastfeeding was $44 \%$ and $65 \%$ among employed and unemployed mothers respectively. Employed mothers were 32\% times less likely to breast feed exclusively than the unemployed mothers $(\mathrm{OR}=0.32)$. Place of birth $(\mathrm{OR}=4.4)$, belief of breast milk sufficiency $(\mathrm{OR}=3.6)$, religious fathers support of exclusive breastfeeding $(\mathrm{OR}=2.7)$ and maternal age of $18-23(\mathrm{OR}=9.4)$ were independently predictors of exclusive breastfeeding among employed mothers. Whereas, husbands' support of exclusive breastfeeding $(\mathrm{OR}=1.9)$, knowledge on duration of exclusive breastfeeding $(\mathrm{OR}=2.8)$, timely initiation of breastfeeding $(\mathrm{OR}=2.9)$, Awareness of exclusive breastfeeding $(\mathrm{OR}=2.2)$ and delivery attendance $(\mathrm{OR}=2.2)$ were independently predictors of exclusive breastfeeding among unemployed mothers. Conclusions: A large proportion of infants are not exclusively breastfed. Exclusive breastfeeding status of unemployed mothers was significantly better than that of employed mothers. Therefore, the government should promote exclusive breastfeeding by creating breastfeeding friendly working environment.
\end{abstract}

Keywords: Exclusive Breast Feeding, Maternal Employment, Injibara Town

\section{Introduction}

Promotion of exclusive breastfeeding is the single most cost-effective intervention to reduce infant mortality in developing countries [1-5]. Non-exclusive breastfeeding has long-term impact, including poor school performance, reduced productivity, and impaired intellectual and social development. It can also increase the risk of dying due to diarrhea and pneumonia among $0-5$ month old infants by more than two-fold [2,3].

Diarrhea and pneumonia are more common and more severe in children who are artificially fed, and are responsible for many of these deaths [6]. Many newborns are neither breastfed during their first hours of life with colostrums nor exclusively breastfed during their first six months; instead, they are given liquids and complementary food at an early age. Only one in three Ethiopian children age 4-5 months is exclusively breastfed. These practices may expose them to infectious diseases, and therefore have a negative impact on their growth and development [7]. 
Evidence shows that $65 \%$ of under-five mortality is caused by malnutrition; more than two-thirds of those are associated with improper breastfeeding practices during infancy. Exclusive breastfeeding for the first six months has greater benefit for the prevention of mother to child transmission of HIV [7]. Worldwide, only $35 \%$ of infants are exclusively breastfed during their first four months of life [2, 3, and 5].

There has been an information gap regarding magnitude and determinant of exclusive breastfeeding among employed and unemployed mothers until now. This study explored magnitude and determinant of exclusive breastfeeding among employed and unemployed mothers in Injibara Town, Awi Zone, North West Ethiopia, 2013.

\section{Methods and Materials}

\subsection{Study Area and Period}

The study was conducted from March 24-April 14, 2013 in Injibara Town, Awi Zone Northwest Ethiopia. Awi Zone is one of the 11 Zones in the Amhara Region of Ethiopia. The administrative center of Awi zone is Injibara. Injibara is located at $122 \mathrm{~km}$ from Bahir Dar and $436 \mathrm{~km}$ from the capital of Addis Ababa. According to 2007 Ethiopian housing and population census, the total population size of the three kebeles were 26,073 .

\subsection{Study Design}

A community- based comparative cross- sectional study design was employed.

\subsection{Source Population}

All employed and unemployed mothers of children age $\leq 1$ year.

\subsection{Study Population}

All employed and unemployed mothers of children age $\leq 1$ year.

\subsection{Sample Size}

Census was conducted to Assess magnitude and determinant of exclusive breastfeeding among employed and unemployed mothers of children age $\leq 1$ year. The total numbers of employed and unemployed mothers of children age $\leq 1$ year were 524 (243 employed and 281 unemployed) who were already registered in Health extension workers' document.

\subsection{Measurements}

The data were collected using a validated questionnaire adapted from the Ethiopian Health and Demographic Survey (EDHS), WHO and LINKAGE project which were designed to assess infant and young child feeding practices in developing countries including Ethiopia [8, 9 and 10]. The questionnaire includes socio-demographic characteristics (14 items), predisposing factors (13 items) enabling factors (4 items) and reinforcing factors ( 8 items) exclusive breast feeding ( 2 items).

\subsection{Data Collection Techniques}

Five $12^{\text {th }}$ grade complete data collectors and three supervisors (public health professionals) were recruited. Two days training was given for data collectors and supervisors on the purpose of the study, questionnaire, data collection methods, process of assigning study participants, and ethical concerns during data collection.

\subsection{Data Quality}

The questionnaire was translated to Amharic and back translated to English to check consistency. Pre-testing was conducted in $5 \%$ of the sample size in similar areas (Dangila Town) before the actual data collection. A total of two days intensive training was given for all supervisors and data collectors. Double entry verification was done to minimize error.

\subsection{Data Analysis}

Data were checked for completeness and consistency each day after collection. And then entered into Epi data version 3.1 and exported to SPSS 16.0. First, descriptive statistics were computed for the study variables. Next simple logistic regression was performed for each independent variable with the outcome of interest at $\mathrm{p}<0.05$ to consider statistically significant variables. Finally, multiple logistic regression analysis was conducted to determine independent predictors of exclusive breastfeeding.

\subsection{Ethical Consideration}

Ethical permission was obtained from the ethics committee of the College of Public Health and Medical Science, Jimma University. After obtaining ethical approval, written permission was obtained from Awi Zone health department and Injibara Town administration Health Office, and verbal informed consent was obtained from each study subject.

\section{Result}

\subsection{Socio-Demographic Characteristics}

Of the total 524 mothers, 473 of them were participated in the study with a response rate of $90.3 \%$. Regarding employment status, 217(45.8\%) were employed and $256(54.1 \%)$ were unemployed. Concerning the educational status, 205(94.5\%) of employed and 98(38.3\%) of unemployed mothers were secondary and above respectively. Regarding to marital status, majority of the mothers, 212 (97.7\%) of employed and $232(90.6 \%)$ of unemployed were married (Table-1). 
Table 1. Socio-demographic characteristics of employed and unemployed mothers in Injibara Town, March, 2013.

\begin{tabular}{|c|c|c|}
\hline \multirow{2}{*}{ Variables } & \multicolumn{2}{|c|}{ Maternal employment } \\
\hline & Employed(N=217) & Unemployed(N=256) \\
\hline \multicolumn{3}{|l|}{ Maternal age } \\
\hline $18-23$ & $42(19.4)$ & $103(40.2)$ \\
\hline $24-29$ & $119(54.8)$ & $103(40.25)$ \\
\hline$>=30$ & $56(25.8)$ & $50(19.5)$ \\
\hline \multicolumn{3}{|l|}{ Place of resident } \\
\hline Urban & $217(100)$ & $227(88.7)$ \\
\hline Semi-urban & - & $29(11.3)$ \\
\hline \multicolumn{3}{|l|}{ Marital status } \\
\hline Married & $212(97.7)$ & $232(90.6)$ \\
\hline Single & $1(0.5)$ & $7(2.7)$ \\
\hline Divorced & - & $8(3.1)$ \\
\hline Widowed & $1(0.5)$ & $1(0.4)$ \\
\hline Separated & $3(1.4)$ & $8(3.1)$ \\
\hline \multicolumn{3}{|l|}{ Ethnicity } \\
\hline Amhara & $114(52.5)$ & $129(50.4)$ \\
\hline Agaw & $100(46.1)$ & $127(49.6)$ \\
\hline Others & $3(1.4)$ & - \\
\hline \multicolumn{3}{|c|}{ Maternal Education } \\
\hline No education & - & $94(36.7)$ \\
\hline Primary & $12(5.5)$ & $64(25)$ \\
\hline $\begin{array}{l}\text { Secondary and } \\
\text { higher }\end{array}$ & $205(94.5)$ & $98(38.3)$ \\
\hline \multicolumn{3}{|l|}{ Husbands Education } \\
\hline No education & - & $66(25.8)$ \\
\hline Primary & $9(4.1)$ & $87(34)$ \\
\hline $\begin{array}{l}\text { Secondary and } \\
\text { higher }\end{array}$ & 208(95.9) & $103(40.2)$ \\
\hline \multicolumn{3}{|l|}{ Child Sex } \\
\hline Male & $111(51.2)$ & $127(49.6)$ \\
\hline Female & $106(48.8)$ & $129(50.4)$ \\
\hline \multicolumn{3}{|c|}{ monthly income of the $\mathrm{HH}$} \\
\hline$<500$ & $2(0.9)$ & $106(41.4)$ \\
\hline $501-1000$ & $9(4.1)$ & $52(20.4)$ \\
\hline $1001-1500$ & $15(6.9)$ & $40(15.6)$ \\
\hline $1501-2000$ & $38(17.5)$ & $29(11.3)$ \\
\hline$>2000$ & $153(70.5)$ & $29(11.3)$ \\
\hline
\end{tabular}

Abbreviation: HH, Household

\subsection{Predisposing Factors}

Majority 208(95.95\%) of employed and 229(89.5\%) of unemployed mothers had knowledge about breast milk is the best food for infants $<6$ months respectively. Most of the respondents, 209 (96.3\%) of employed and 233(91\%) of unemployed mothers had knowledge about Exclusive Breast Feeding respectively. Almost all mothers, 215(99.1\%) of employed and 237 (92.6\%) of unemployed mothers had knowledge about recommended duration of Exclusive Breast Feeding respectively. Few of the mothers, 3(1.5\%) of employed and $23(9 \%)$ of unemployed had an opinion of infants should breast feed exclusively for $<6$ months respectively.
Table 2. Predisposing factors of employed and unemployed mothers in Injibara town, March, 2013

\begin{tabular}{|c|c|c|}
\hline \multirow{2}{*}{ Variables } & \multicolumn{2}{|c|}{ Maternal employment } \\
\hline & Employed(N=217) & Unemployed( $(\mathrm{N}=256)$ \\
\hline \multicolumn{3}{|c|}{ Best food for infants $<6$ months } \\
\hline Breast milk & 208(95.9) & $229(89.5)$ \\
\hline Formula milk & $6(2.8)$ & $6(2.3)$ \\
\hline Porridge & $1(0.5)$ & $3(1.2)$ \\
\hline Do not know & $2(0.9)$ & $18(7)$ \\
\hline \multicolumn{3}{|c|}{ Advantage of EBF to a mother } \\
\hline prevents disease & $62(28.6)$ & $55(21.5)$ \\
\hline prevents pregnancy & $37(17.1)$ & $33(12.9)$ \\
\hline saves money & $2(0.9)$ & - \\
\hline $\begin{array}{l}\text { bonds mother and } \\
\text { child }\end{array}$ & $76(35.0)$ & $59(23.0)$ \\
\hline do not know & $31(14.3)$ & $107(41.8)$ \\
\hline others & $9(4.1)$ & $2(0.8)$ \\
\hline \multicolumn{3}{|c|}{ Breast milk prevents disease (Child) } \\
\hline Yes & $215(99.1)$ & 209(81.6) \\
\hline No & - & $17(6.6)$ \\
\hline Do not know & $2(0.9)$ & $30(11.7)$ \\
\hline \multicolumn{3}{|c|}{ In your opinion for how long should a child should feed breast milk only } \\
\hline$>=6$ months & $214(98.6)$ & 233(91.0) \\
\hline$<6$ months & $3(1.4)$ & $23(9.0)$ \\
\hline \multicolumn{3}{|l|}{ The meaning of EBF } \\
\hline $\begin{array}{l}\text { Feed only breast } \\
\text { milk }\end{array}$ & $209(96.3$ & 233(91.0) \\
\hline Feed only cow's milk & $2(0.9)$ & - \\
\hline $\begin{array}{l}\text { Feed only formula } \\
\text { milk }\end{array}$ & $1(0.5)$ & $1(0.4)$ \\
\hline Feed breast milk & $3(1.4)$ & $9(3.50$ \\
\hline porridge & $2(0.9)$ & $13(5.1)$ \\
\hline $\begin{array}{l}\text { Role of husband in } \\
\text { EBF Advice on EBF }\end{array}$ & $57(26.3)$ & $47(18.4)$ \\
\hline $\begin{array}{l}\text { Give economic } \\
\text { support }\end{array}$ & 154(71.0) & $162(63.3)$ \\
\hline Has no role & $4(1.8)$ & 28(10.9) \\
\hline Do not know & $2(0.9)$ & 18(7.0) \\
\hline \multicolumn{3}{|c|}{ Recommended duration of EBF } \\
\hline Birth-6 months & $215(99.1)$ & $237(92.6)$ \\
\hline Birth-4 months & $2(0.9)$ & $19(7.4)$ \\
\hline \multicolumn{3}{|c|}{ Breast milk is better than infant formula } \\
\hline Yes & $215(99.1)$ & $210(82.0)$ \\
\hline No & $1(0.5)$ & $28(10.9)$ \\
\hline Do not know & $1(0.5)$ & $18(7.0)$ \\
\hline \multicolumn{3}{|c|}{ Breast milk sufficiency for the first 6 months } \\
\hline Yes & $160(73.7)$ & $163(63.7)$ \\
\hline No & $57(26.3)$ & $93(36.3)$ \\
\hline \multicolumn{3}{|c|}{ Do you think that to start breast feed straight after delivery? } \\
\hline Yes & $205(94.5)$ & $236(92.2)$ \\
\hline No & $11(5.1)$ & $20(7.8)$ \\
\hline \multicolumn{3}{|c|}{ Do you think that women should not breast feed public places? } \\
\hline Yes & $34(15.7)$ & $40(15.6)$ \\
\hline No & $181(83.4)$ & $187(73.0)$ \\
\hline Do not know & $2(0.9)$ & $29(11.3)$ \\
\hline \multicolumn{3}{|c|}{ Religious fathers encourage EBF } \\
\hline Yes & 101(46.4) & $149(80.6)$ \\
\hline $\mathrm{No}$ & $116(53.2)$ & $107(57.9)$ \\
\hline
\end{tabular}

Abbreviation: EBF, exclusive breastfeeding 
Overall, Majority of the respondents 194 (89.4\%) employed and 137(53.5\%) unemployed were knowledgeable about Exclusive Breast Feeding respectively. Two hundred ten $(96.8 \%)$ employed and $182(71.1 \%)$ unemployed mothers had favorable attitude towards Exclusive Breast Feeding respectively. And 152(70\%) employed and 179(69.9\%) unemployed had the positive belief towards Exclusive Breast Feeding respectively (Table-2).

\subsection{Enabling Factors}

Majority, 188(86.6\%) of employed and 242 (94.5. \%) of unemployed mothers visited the health facility during their pregnancy. $141(75 \%)$ of employed and $97(40 \%)$ of unemployed mothers visited the health facility 4 times during their pregnancy respectively. Regarding to health information, $154(81 \%)$ of employed and $166(69 \%)$ of unemployed mothers were informed about Exclusive Breast Feeding respectively.

\subsection{Reinforcing Factors}

Table 3. Reinforcing factors of employed and unemployed mothers in Injibara Town, March, 2013.

\begin{tabular}{|c|c|c|}
\hline \multirow{2}{*}{ Variables } & \multicolumn{2}{|c|}{ Maternal employment } \\
\hline & Employed(N=217) & Unemployed $(\mathrm{N}=256)$ \\
\hline \multicolumn{3}{|l|}{ Place of delivery } \\
\hline home & $32(14.7)$ & $78(30.5)$ \\
\hline health facility & $185(85.3)$ & $178(69.6)$ \\
\hline \multicolumn{3}{|l|}{ Birth attendance } \\
\hline $\begin{array}{l}\text { Health } \\
\text { professionals }\end{array}$ & 191(88.0) & $168(65.6)$ \\
\hline $\begin{array}{l}\text { Non-health } \\
\text { professional }\end{array}$ & $26(12)$ & $88(34.3 \%$ \\
\hline \multicolumn{3}{|l|}{ Mode of delivery } \\
\hline Vaginal delivery & $190(87.6)$ & $250(97.7)$ \\
\hline Caesarian section & $27(12.4)$ & $6(2.3)$ \\
\hline \multicolumn{3}{|c|}{ Timely initiation of $\mathbf{B F}$ (within one hour) } \\
\hline Yes & $205(94.5)$ & $236(92.2)$ \\
\hline No & $11(5.1)$ & $20(7.8)$ \\
\hline \multicolumn{3}{|c|}{ Mass media encourage EBF } \\
\hline Yes & $210(96.8)$ & $154(60.2)$ \\
\hline No & $7(3.2)$ & $102(39.8)$ \\
\hline \multicolumn{3}{|c|}{ Family support of EBF } \\
\hline Yes & 197(90.8) & $180(70.3)$ \\
\hline No & $20(9.2)$ & $76(29.7)$ \\
\hline \multicolumn{3}{|c|}{ Husband support of EBF } \\
\hline Yes & $201(92.6)$ & $187(73.0)$ \\
\hline No & $16(7.4)$ & $69(27.0)$ \\
\hline
\end{tabular}

Abbreviation: EBF, exclusive breastfeeding

Above fourteen percent of employed and thirty percent of unemployed mothers delivered at home. From total study participants, $26(12 \%)$ of employed and $88(34.3 \%)$ of unemployed mothers were delivered by non-health professionals. From total study participants, 205(94.5\%) of employed and $236(92.2 \%)$ of unemployed mothers breast feed their children within one hour. Majority, 210(96.8\%) of employed and more than half $154(60.2 \%)$ of unemployed mothers had an access of mass media. Majority, 210(92, 6\%) of employed and 187(73\%) of unemployed mothers were supported by their husbands about Exclusive Breast Feeding (Table-3).

\subsection{Prevalence of Exclusive Breast Feeding}

The study revealed that the prevalence of exclusive breastfeeding practice was Forty four percent and 65\% among employed and unemployed mothers respectively.

\subsection{Comparison of Exclusive Breast Feeding among Employed and Unemployed Mothers}

Maternal employment status, health information about exclusive breast feeding, husbands' support on exclusive breast feeding, Perception about exclusive breast feeding and timely initiation of $\mathrm{BF}$ were significantly associated with exclusive breast feeding among employed and unemployed mothers. Employed mothers were $32 \%$ times less likely to breast feed exclusively than unemployed mothers $(\mathrm{OR}=0.32 \mathrm{P}<0.001)$.

\subsection{Independent Predictors of Exclusive Breast Feeding for Unemployed Mothers}

Table 4. Multivariate analysis of exclusive breast feeding among unemployed mothers in Injibara Town, March, 2013

\begin{tabular}{|c|c|c|c|c|}
\hline \multirow[b]{2}{*}{ Variable } & \multicolumn{2}{|c|}{ Exclusive Breast Feeding Status } & \multirow[b]{2}{*}{ COR } & \multirow[b]{2}{*}{ AOR } \\
\hline & $\begin{array}{l}\text { Non-Exclusive } \\
(\%)\end{array}$ & N1 Exclusive N2 (\%) & & \\
\hline \multicolumn{5}{|c|}{ family support EBF } \\
\hline Yes & $55(61.8)$ & $125(74.9)$ & 1 & 1 \\
\hline No & $34(38.2)$ & $42(25.1)$ & $1.8 * *$ & 0.8 \\
\hline \multicolumn{5}{|c|}{ Husband support EBF } \\
\hline Yes & $55(61.8)$ & $132(79)$ & 1 & 1 \\
\hline No & $34(38.2)$ & $35(21)$ & $2.3 * *$ & $1.9 * *$ \\
\hline \multicolumn{5}{|c|}{ Recommended duration of EBF } \\
\hline Yes & $77(86.5)$ & $160(95.8)$ & 1 & 1 \\
\hline No & $12(13.5)$ & $7(4.2)$ & $3.6 * *$ & $2.8 * *$ \\
\hline \multicolumn{5}{|c|}{ Sufficiency of breast milk in the first 6 months } \\
\hline Yes & $49(55.1)$ & $114(68.3)$ & 1 & 1 \\
\hline No & $40(44.9)$ & $53(31.7)$ & $1.8 * *$ & 1.7 \\
\hline \multicolumn{5}{|c|}{ Timely initiation of BF } \\
\hline Yes & $77(86.5)$ & $159(95.2)$ & 1 & 1 \\
\hline No & $12(13.5)$ & $8(4.8)$ & $3.1 * *$ & $2.9 * *$ \\
\hline \multicolumn{5}{|l|}{ Mass media } \\
\hline Yes & $45(50.6)$ & $109(65.3)$ & 1 & 1 \\
\hline No & 44(49.4) & $58(4.7)$ & $1.8 * *$ & 1.4 \\
\hline \multicolumn{5}{|c|}{ Health information. on EBF at ANC } \\
\hline Yes & $65(73)$ & $146(87.4)$ & 1 & 1 \\
\hline No & $24(27)$ & $21(12.6)$ & $2.6^{* *}$ & $2.2 * *$ \\
\hline \multicolumn{5}{|c|}{ Delivery attendance } \\
\hline $\begin{array}{l}\text { Health } \\
\text { professional }\end{array}$ & $62(69.7)$ & $142(85)$ & 1 & 1 \\
\hline $\begin{array}{l}\text { Non-health } \\
\text { professional }\end{array}$ & $27(30.3)$ & $25(15)$ & $2.5 * *$ & $3.0 * *$ \\
\hline
\end{tabular}

Note: **Indicates significant at $P<0.05$. Abbreviation: EBF, exclusive breastfeeding, COR, Crude odd ration and AOR, adjusted odds ratio.

Mothers who were not supported by their husbands were 1.9 times more likely to not breast feed exclusively than 
those who were supported $(\mathrm{OR}=1.9)$. Mothers who had no Knowledge about the recommended duration of EBF were 2.8 times more likely to not breast feed exclusively than those who had Knowledge $(\mathrm{OR}=2.8)$. Mothers who didn't practiced timely initiation of BF were 2.9 times more likely to not breast feed exclusively than who practiced $(\mathrm{OR}=2.9)$. Mothers who did not get health information about exclusive breastfeeding were 2.2 times more likely to not breast feed exclusively than those who got $(\mathrm{OR}=2.2)$. Those mothers who were delivered by non- health professionals were 3.0 times more likely to not breast feed exclusively than those who were delivered by health professionals $(\mathrm{OR}=$ 3.0(Table-4)

\subsection{Independent Predictors of Exclusive Breast Feeding for Employed Mothers}

Place of birth, religious fathers encourage of exclusive breastfeeding and maternal ages of 18-23 were independent predictors of exclusive breast feeding of employed mothers. Mothers who delivered at health facility were 4.4 times more likely to breast feed exclusively than those who delivered at home $(\mathrm{OR}=4.4)$. Mothers who were encouraged by religious fathers about EBF were 2.7 times more likely to breast feed exclusively than those who were not encouraged $(\mathrm{OR}=2.7)$. Mothers whose ages of 18-23 were 9 times more likely to breast feed exclusively than those whose ages were thirty and above $(\mathrm{OR}=9.4)($ table 5$)$.

Table 5. Multivariate analysis of exclusive breast feeding among employed mothers in Injibara Town, March, 2013

\begin{tabular}{|c|c|c|c|c|}
\hline \multirow{3}{*}{ Variable } & \multicolumn{2}{|c|}{ Exclusive Breast Feeding Status } & \multirow{3}{*}{ COR } & \multirow{3}{*}{ AOR } \\
\hline & Not Exclusive & Exclusive & & \\
\hline & N1 (\%) & $\mathrm{N}_{2}(\%)$ & & \\
\hline \multicolumn{5}{|c|}{ ANC follow up } \\
\hline Yes & $98(81)$ & $90(93.8)$ & 1 & 1 \\
\hline No & $23(19)$ & $6(6.2)$ & $3.5 * *$ & 4.2 \\
\hline \multicolumn{5}{|c|}{ Place of delivery } \\
\hline Home & $43(35.5)$ & $18(18.8)$ & 1 & 1 \\
\hline $\begin{array}{l}\text { Health } \\
\text { facility }\end{array}$ & $78(64.5)$ & $78(81.2)$ & $2.4 * *$ & $4.4 * *$ \\
\hline \multicolumn{5}{|c|}{ Family support on EBF } \\
\hline Yes & $105(86.8)$ & $92(95.8)$ & 1 & 1 \\
\hline No & $16(13.2)$ & $4(4.2)$ & $3.3 * *$ & 0.2 \\
\hline \multicolumn{5}{|c|}{ Husband support on EBF } \\
\hline Yes & $108(89.3)$ & 93(96.9) & 1 & 1 \\
\hline No & $13(10.7)$ & $3(3.1)$ & $3.7 * *$ & 2.7 \\
\hline \multicolumn{5}{|c|}{ Advantage on EBF } \\
\hline Yes & $89(73.6)$ & $88(91.7)$ & 1 & 1 \\
\hline No & $32(26.4)$ & $8(8.3)$ & $4.0 * *$ & 1.7 \\
\hline \multicolumn{5}{|c|}{ Religious fathers encourage on EBF } \\
\hline Yes & $52(65)$ & $32(66.7)$ & $3.7 * *$ & $2.7 * *$ \\
\hline $\mathrm{No}$ & $16(13.2)$ & $16(33.3)$ & 1 & 1 \\
\hline \multicolumn{5}{|c|}{ Maternal age } \\
\hline $18-23$ & $16(13.2)$ & $26(27.1)$ & 2.3 & $9.4 * *$ \\
\hline 24-29 & $72(59.5)$ & $47(49)$ & 0.9 & 0.9 \\
\hline$>=30$ & $33(27.3)$ & $23(24)$ & 1 & 1 \\
\hline
\end{tabular}

Note: **Indicates significant at $P<0.05$. Abbreviation: EBF, exclusive breastfeeding, COR, Crude odd ration and AOR, adjusted odds ratio.

\section{Discussion}

This study aimed to determine the prevalence of exclusive breastfeeding and associated factors among employed and unemployed mothers. The study revealed that the prevalence of exclusive breastfeeding practice was $44 \%$ and $65 \%$ among employed and unemployed mothers respectively. This finding is higher among employed and lower among unemployed mothers compared to the study conducted in Ethiopia [11]. The possible difference might be different Study population.

Employed mothers were $32 \%$ times less likely to exclusively breastfeed than unemployed mothers. This finding is in agreement with the study conducted in Guatemala City; which speaks out that women who were not work outside the home were $32 \%$ times as likely to exclusively breastfeed as were women who worked outside the home [12]. Due to variations in maternal time, the majority of employed mothers started feeding their children with liquids and foods supplementations earlier before the age of weaning when compared to their unemployed counterparts, hence early termination of breastfeeding was observed more in employed mothers than in unemployed mothers. Thus, employed mothers were obliged to leave their children with somebody else who care for their children.

Extensive body research suggests that if adequate alternative childcare is available, there are no negative impacts of mother's employment on the child. However, in the much more economically and environmentally stressed situation in which many Ethiopian women live, this conclusion may not hold. Therefore, due to all these facts, children of employed mothers were at the disadvantage with regard to childcare and feeding practices. Thus, these improper feeding practices increase the chance of child's malnutrition compared to children of unemployed mothers that benefited from mothers who stays at home. Hence, the overall net effects of maternal employment (economic gain) and the costs of reduced time of the mother in childcare cancel out each other and drew the relationship to the null value. This was consistent with other study by Barry M. Popkin [13].

Unemployment of the mothers is a predictor of exclusive breastfeeding. This finding similar to the study conducted in Sudan, Malaysia and by Taveras, Chudsama [14-17]. The possible reason might be less maternity leave (three months in our context), which makes employed mothers have less opportunity to stay at home, compromising exclusive breastfeeding and facilities for breastfeeding at work places are not available in our case. This situation would discourage employed mothers from exclusively breast feed as compared to unemployed mothers.

Employed mothers whose age's b/n 18-23 were 9 times more likely to breast feed than those above thirty years old. This result is consistent with the study conducted in Syrian and Jordanian which depicts that, women aged 25 or less was more likely to practice exclusive breastfeeding compared with those whose' ages were older than 25 years[18-21]. The 
possible reason might be breastfeeding promotion through media, currently inclusion of breastfeeding benefits in school curriculum and younger mothers are more sensitive for breast feeding. Initiation of breastfeeding within one hour of delivery and ANC visits were positively associated with exclusive breastfeeding among employed and unemployed mothers. This finding is in line with the study conducted in Geneva [2, 22].

\section{Conclusion}

The prevalence of exclusive breastfeeding practice was low in both among employed and unemployed mothers. This study has indicated a significant difference among employed and unemployed mothers with regard to exclusive breastfeeding. Employed mothers are less likely to exclusively breastfeed than unemployed mothers. Husbands' support on exclusive breastfeeding, knowledge of recommended duration of exclusive breastfeeding, Timely initiation of breast feeding, Delivery attendance and Health information about exclusive breastfeeding are Independent predictors of Exclusive breast feeding of unemployed mothers. Every stakeholder should promote exclusive breastfeeding through creating breastfeeding friendly working environment for working mothers. Planners should consider the significantly associated factors among employed and unemployed mothers while designing an intervention exclusive breastfeeding.

\section{Acknowledgment}

We acknowledge the professional assistance of Jimma University in undertaking this research. We would also like to express our gratitude to Awi Zone health desk and respective health facilities for their full cooperation and the study participants. Our thanks also go to the data collectors and supervisors.

\section{Disclosure}

The authors declare that they have no conflicts of interest in this work.

\section{Reference}

[1] World Health Organization: The optimal duration of exclusive breastfeeding: report of an expert consultation. Geneva: World Health Organization, Department of nutrition for Health and development and department of child and adolescent health and development, 2001.

[2] World Health Organization: Global strategy for infant and young child feeding. The Optimal duration of exclusive breastfeeding. Geneva: World Health Organization, 2001.

[3] World Health Organization: Infant and young child feeding (IYCF) Model Chapter for Textbooks for medical students and allied health professionals. Switzerland: World Health Organization, 2009.
[4] Shenyang R, Muwonge R, and Nankya I. towards a Better Understanding of Exclusive Breastfeeding in the Era of HIV/AIDS: A Study of Prevalence and Factors Associated With Exclusive Breastfeeding from Birth, in Rakia, Uganda. Journal of Tropical Pediatrics, 2004, 50:348-53.

[5] Fjeld E, Siziya S, Katepa-Bwalya M, Kankasa C, Moland KM PROMISE-EBF Study Group: No sister, the breast alone is not enough for my baby' a qualitative Assessment of potentials and barriers in the promotion of exclusive breastfeeding in Southern Zambia. Int Breastfeed J .2008, 3:26.

[6] WHO, Infant and young child feeding: model chapter for textbooks for medical Students and Allied health professionals, 2009.

[7] Central Statistical Agency. Demographic and health survey 2005, Ethiopia ORC Macro Calverton, Maryland, USA September, 2006.

[8] Central Statistical Agency [Ethiopia] and ORC Macro: Ethiopia Demographic and Health Survey (EDHS) 2005. Addis Ababa, Ethiopia and Calverton, Maryland, USA: Central Statistical Agency and ORC Macro, 2006.

[9] World Health Organization: Infant and young child feeding (IYCF) Model Chapter for Textbooks for medical students and allied health professionals. Switzerland: World Health Organization, 2009.

[10] Binns CW, Fraser ML, and Lee AH, Scott J. Defining exclusive breastfeeding in Australia. J Paediatr Child Health 2009, 45:174-180.

[11] Tesfaye S. et al, exclusive BF and associated factors among mothers in Goba woreda, bale Zone, Southeast Ethiopia. International Breastfeeding Journal, 2012, 7:17; 1-18.

[12] Dearden, K. Altaye, M. De Maza. Determinants of optimal breastfeeding in peri Urban Guatemala City, Guatemala. Rev Panam Salud Publica, 2002.

[13] Barry M. Popkin. Time allocation of the Mother and Child Nutrition. Ecology of Food and Nutrition; 1980; 9: 1-14.

[14] Haroun HM, Mahfouz MS, Ibrahim. Breast feeding indicators in Sudan: a case Study of Wad Medani town. Sudanese J Public Health 2008, 3:81-90.

[15] Tan KL: Factors associated with exclusive breastfeeding among infants less than six Months of age in peninsular Malaysia. Int Breastfeed J 2011, 6:2.

[16] Taveras EM, Capra, Braveman PA, Jensvold NC, Escobar GJ, Lieu TA. Clinician Support and psychosocial risk factors associated with breastfeeding discontinuation. Pediatrics 2003, 112:108-115.

[17] Chudasama R. Patel P. \& Kavishwar A. Breastfeeding initiation practice and factors Affecting breastfeeding in South Gujarat region of India. The Internet Journal of Family Practice, 2009.

[18] Tiwari, R. Mahajan, P. C. Lahariya, C. The determinants of exclusive breast feeding in urban slums: a community based study. Trop Pediatr, 2009.

[19] Senarath U. Dibley M.J. and Agho K.E. Breastfeeding practices and associated factors among children under 24 months of age in Timor Leste. European Journal of Clinical Nutrition, 2007. 
[20] Mclnnes RJ, Love JG, Stone DH. Independent predictors of breastfeeding intention in A Disadvantaged population of pregnant women. BMC Public Health 2001, 1:10

[21] Mitra AK, Khoury A, Hinton AW, Carothers C: Predictors of breastfeeding Intention Among low-income women. Maternal and Child Health Journal 2004, 8:65-70.
[22] Leung TF, Tam WH, Hung E, Fok TF, Wong G. Sociodemographic and atopic Factors Affecting breastfeeding intention in Chinese mothers. Journal of Pediatrics and Child Health 2003, 39:460-464. 